\title{
Critical Review of the Malawi Community Energy Model
}

\author{
P.M. Dauenhauer, D.F. Frame \\ Department of Electronic and Electrical Engineering \\ University of Strathclyde \\ Glasgow, Scotland \\ \{peter.dauenhauer, damien.frame\}@strath.ac.uk
}

\begin{abstract}
Over the past decade, promotion of innovative models for distributed renewable energy supply in developing countries has grown considerably. International plans to meet goals of universal energy access and increased use of renewables depend on the success of these projects. This paper considers the community energy model demonstrated in the Malawi Renewable Energy Acceleration Programme (MREAP). Initial indications suggest a significant improvement in the sustainability prospects of the associated community energy projects at the cost of a higher investment in the development process. The potential of the model is clear, yet the systematic challenges to sustainability for off-grid systems in Malawi require an ongoing support mechanism for communities, ostensibly through a district energy office.
\end{abstract}

Index Terms - Community Energy, Distributed power generation, Energy Poverty, Sustainable development, Renewable Energy Sources

\section{ENERGY ACCESS WORLDWIDE \& IN MALAWI}

Despite recent gains and advances in technology, sustainable energy access remains elusive for poor communities living in remote areas of the world. Roughly 1.3 billion people are estimated to have no access with many more experiencing unreliable or unaffordable connections [1]. The power industry has traditionally been the exclusive domain of national governments to develop with privatization and liberalization, otherwise known as deregulation, occurring only after its development. In many developing countries, the government-led power sector development process is stagnant, [2] yet access to reliable and affordable energy services is critical for sustainable development in general [3]-[4]; it is an enabling factor for both the private and public sectors.

The potential of off-grid access as a solution is now highly touted due to a confluence of factors: the rapid decrease in costs of generation technologies (e.g. solar photo-voltaics), proliferation of energy efficient consumer products (e.g. LED lights, mobile phones), and the appearance of disruptive technologies (i.e. cloud-/mobile- based) [5]-[6]. This prospect is exciting as a potential alternative to government-led grid development. Nonetheless, the sustainability challenges for communities and entrepreneurs to succeed, with (or in spite of) a weak institutional environment or with poor infrastructure, as is common in low-income countries, cannot be underestimated.

Universal energy access, a goal of the UN Sustainable Energy for All Initiative (SE4ALL), is expected to rely heavily on successful deployment of distributed generation for the countries that currently do not have large interconnected grids, with a large proportion gaining access through minigrids, stand-alone systems, and 'pico-' products by 2040 [7]. According to the most recent estimates, only $9 \%$ of Malawi's 16 million are connected to the main grid. In rural areas, this is roughly $1 \%$ [7]. Overall energy consumption is dominated by the use of traditional biomass at $89 \%$ of the total [8]. Current efforts to reach underserved locales with electricity access consists primarily of grid extension by the Malawi Rural Electrification Programme (MAREP). As was presented in 2015 by a Department of Energy Affairs official, MAREP has to-date connected 137 trading centers throughout the country [9]. Major institutional reform efforts are also underway with ESCOM, the national utility, to build capacity and restructure the industry to allow for external energy investments [10]. Despite these encouraging steps, overall slow progress of grid extension has driven interest in grass roots approaches that promise a more immediate solution for the energy impoverished.

Currently low electrification rates at rural public facilities such as primary schools and health centers [11]-[12], are due in part to the singular and insufficient approach to electrification by the government. Grid extension naturally prioritizes urban facilities which exacerbates a differential of qualities of services provided. Furthermore, there is a standing institutional gap where no energy-related offices exist at the district level that could promote and support alternative. All (known) alternative off-grid electrification at these facilities has been led by international donors with the energy point of local community management of the projects. With SE4ALL, Malawi is in a position to coordinate investments 
into the off-grid market but needs to ensure these investments achieve the intended effects. Thus, a key question for Malawian policy markers today is: how appropriate is the community energy model based on these experiences; how far has it come, and what challenges remain?

This paper provides an important contribution to the literature on models for delivery of off-grid energy in developing communities. For Malawi in particular, we provide critical evidence and analysis on the current state of community energy models, its benefits, and challenges to implemention. Likewise there is international relevance since the trend continues for communities assuming an ever larger role in developing, supporting, and even operating distributed power systems.

In Section II the paper begins by analyzing results from a survey in Malawi to uncover the sustainability challenges in the off-grid space in Malawi. We then describe the Malawi Renewable Energy Acceleration Programme's (MREAP) [13] Community Energy Development Programme (CEDP) case study through its process of development, the community energy model used (Section III) and its major achievements through 2015 (Section IV). Section V critically analyzes the model with respect to known sustainability issues and concludes (Section VI) with our implications for scaling up the model.

\section{SUSTAINABILITY OF COMMUNITY ENERGY PROJECTS}

\section{A. The Sustainability Challenge}

Through the initial scoping and evaluation stages of MREAP, sustainability of off-grid PV systems was identified as a major issue for community renewable energy development in Malawi [13]. The distinct lack of an evidence base from which learning can be drawn to inform stakeholders deploying renewable energy systems in Malawi and wider policy making was also highlighted. In response, a study was commissioned to investigate sustainability issues in 45 systems throughout the country [14]. The purpose was to better describe the systems, identify which systems were still functioning and most importantly to uncover issues that have led to poor sustainability. The approach to survey design was based on the concept of sustainability pillars (technical, economic, social and organizational) which formed distinct sections in the survey with relevant indicators and questions.

\section{1) Technical Sustainability}

From this study, overall system technical performance was considered poor with large numbers of systems not meeting expectations of the users. Specific issues were: PV panel orientation and mounting was not always correct, high numbers of what could be deemed to be 'inferior' components being installed, uncontrolled inverter load was common (inverter connected directly to batteries), system design practices erred on the side of optimistic/minimum (budget) assumptions rather than preferring technically robust specifications, and chronic under-specification of battery banks appeared to be a particular issue. These issues manifested in an observed performance of: $38 \%$ of the systems had completely lost all service, $58 \%$ of room lighting was not fully meeting expectations, $43 \%$ of batteries were showing 'bad' battery health indicator, and $31 \%$ of the mainly CFL installed bulbs were not working.

\section{2) Economic Sustainability}

Economic sustainability was found to be very poor in the majority of projects. Only 11 projects $(28 \%)$ had any kind of income at all. Of these only 6 (15\% of all projects) also had a bank account. Within the small group of projects that were managing to generate income and had a bank account, there were indications that a community managed financial model could achieve a degree of economic sustainability in terms of meeting running costs if the systems were technically robust and did not experience an unduly high degree of fault.

\section{3) Social Sustainability}

A relatively limited involvement by social actors was observed in many cases. This manifests in a lack of ownership over projects. Nearly half of projects identified no stakeholders involved in the project and $18 \%$ had no 'decision maker'. The difference between these two responses can be interpreted to mean that in some cases 'custodians' of projects step in to make decisions without fully owning the projects. Community consultation at project inception was around $60 \%$ and equally for whether a needs assessment was completed. As a gauge of community ownership or buy-in at inception, almost no projects had any sort of community contribution (and no monetary contributions at all). This suggests that even when the community is consulted, the community had only token involvement.

\section{4) Organizational Sustainability}

From an organizational perspective, half of all projects had no ongoing maintenance arrangements in place and more than half had no process of handover training should a management team member leave. The skill levels and human resources available for project management were extremely low across the set of projects, particular in the area of financial management. The other key capacities of technical skills and managerial skills were similarly not adequately addressed.

\section{5) Overview of Sustainability Issues}

Although there are many perspectives on the subject, the study's authors considered the minimum requirements for a project to be considered 'sustainable' is if it maintains sufficient technical performance to meet usage expectations, has relatively strong financial performance, is embedded and accepted within the community, and has sufficient skill-levels to manage the project. Evaluation of sustainability is complicated by the interaction between these factors. It is essential that systems are sufficiently technically robust to maintain a reliable level of performance but appropriately scaled such that the available financial resources can support its operation. Whilst community engagement, existence of organized social and managerial structures are also of importance, a low standard of system design manifesting in low reliability will undermine the ability of the project to be economically sustainable. The evidence suggests that systems installed in Malawi prior to MREAP were rarely able to achieve a high standard of sustainability. 
III. Community Energy Development Programme PROCESS AND MODEL

The community energy model under CEDP was aimed at achieving highly sustainable projects through significant investment in a community based development approach. In Malawi, Community Based Organizations (CBOs) have often been established to mobilize communities or respond to specific issues such as HIV/AIDS awareness. In the past, CBOs have generally had a good reputation as an effective vehicle for communities to respond to their needs. Because of their mandate to respond to community needs as well as being a permanent governance structure, $\mathrm{CBOs}$ were chosen as the entry point for CEDP community energy projects.

A process evaluation was conducted under CEDP which captured the process for which $\mathrm{CBOs}$ were identified and selected in the program [15]. $12 \mathrm{CBOs}$ were selected through a consultative process at 12 District Executive Committees (DEC). Districts and sub-region of operation was based on several criteria including poverty levels and likelihood of the grid arriving in the near future. Sensitization meetings were held to describe the project objectives and prospective technologies. Multiple CBOs in each district indicated their interest and willingness to take on the project. The DECs provided historical records of the $\mathrm{CBOs}$ and provided feedback on each CBOs level of organization and performance in past projects. Prospective CBOs in each district completed a grant application where their records and readiness for the project was assessed. CEDP development officers evaluated these applications and selected the most promising $\mathrm{CBO}$ in each district. Detailed feedback was returned to the unsuccessful CBOs in hopes that they could reapply in future opportunities. Successful CBOs undertook capacity building activities led by the development officers. Skills requirements were assessed using a basic audit form. This included training activities to further familiarize the communities with energy technologies and learn specifically about technical, managerial and financial project management.

\section{A. Sustainability Features}

\section{1) Technical Sustainability}

Tackling technical sustainability started with a baseline and needs assessment process undertaken by the development officers to ascertain the specific energy needs of the community. The needs assessment involved community members from different stakeholder groups. A baseline captured current energy use and expenditure information for community members. Installations required suitably accredited suppliers followed by Malawi Energy Regulatory Authority (MERA) inspection.

\section{2) Economic Sustainability}

Business models were jointly developed by the community and development officers to underpin the project finances. Outside the community contributions and external funds (provided through CEDP for capital and development costs only), income was assumed to be self-generated since there was no public financial support from district offices. Each $\mathrm{CBO}$ had to identify revenue generating activities (RGA) and typical RGAs included mobile phone charging, running a barber shop, selling solar lanterns, screening television shows, and providing solar home systems at teacher houses for a monthly fee. Typical costs included security guards, replacement of light bulbs, charge controllers, and station batteries. Monthly savings targets were established to cover costs over time. CBOs established a project bank account and created a structure of transparent oversight of the accounts. A financial community contribution (less than $1 \%$ of overall grant) was raised.

\section{3) Social Sustainability}

The project initiation process described above was designed around the principals of community engagement, sensitization and capacity building. Stakeholders from local government, through local development groups to individual community members were involved throughout all stages of the project resulting in the ownership and operation structure outlined below. Through the selection process, identification of effective CBOs, which were themselves permanent entities that had community support, ensured that the organization itself could represent (and respond to) community needs.

\section{4) Organizational Sustainability}

In CEDP, the CBO was responsible for overall management, local project support, and ensuring asset management. The local operators are responsible for operating and utilizing the systems according to the agreed needs and RGA activities. Once handed over to the community, operation of the project was shared between $\mathrm{CBO}$ and individual project owners. The ownership model was developed with explicit input of each community as to what arrangement would be desirable. As such, there was a degree a variation. In general, a $\mathrm{CBO}$ would oversee several individual projects which would each have a local committee to manage day-to-day operations and revenue generation. Intra-project revenue sharing was generally established so that should one project under a $\mathrm{CBO}$ experience a fault, it could utilize the revenues of the entire group to fund the maintenance. Local operators, usually a newly created energy management committee formed around a school committee, were responsible for ensuring the desired use of the system, running RGAs, handling money, and liaising with the CBO to manage funds. The committee was entirely voluntary. Small monthly salary payments were made to security and RGA operators, equivalent to less than \$10 USD.

\section{5) Ongoing Support Organization}

Community Energy Malawi (CEM) emerged from the development process of the CEDP projects and was a further sustainability mechanism. This organization was formed from the CEDP development officers and assumed a continuous support role for the communities involved. This was crucial as, lacking any public provision which could support the communities, CEM could periodically assess and address community needs, reinforce the project management structure, conduct training, and share information on best practice. However, since CEM itself requires funding sources itself, both the sustainability of its own operation and the projects themselves are linked. 


\section{CEDP MAIN ACHIEVEMENTS 2012-2015}

Under CEDP, 46 distinct community energy projects were established in 12 districts in Malawi. It was estimated that 20,439 Malawians benefited from these interventions. MREAP, as a whole, also piloted 4 "Strategic Energy Projects" and was estimated to directly impact 78,875 people through the projects [13]. Technology choice and application within CEDP were varied as communities had an ability to decide this factor. The mix of projects types is shown in Table I.

In a follow-up process evaluation in 2015 [15], projects were reviewed after 6 months of operation. While still young in terms of overall project lifespan, immediate performance of the projects can be critical for its long-term success. The evaluation found the installed projects to be highly relevant to the communities, especially in the area of improving educational quality and building business skill capacity of the CBO. At the 6-month point, the projects were estimated to be $93 \%$ functional, a relatively high rate given the functionality of comparable systems in Malawi around 40\% [14].

TABLE I. CEDP PROJECT TECHNOLOGY AND APPLICATIONS

\begin{tabular}{|l|c|c|c|l|}
\hline \multirow{2}{*}{\multicolumn{1}{|c|}{ Application }} & \multicolumn{5}{c|}{ Region } \\
\cline { 2 - 5 } & Central & North & South & Total \\
\hline Lighting - CBO offices & & 2 & 1 & 3 \\
\hline Lighting - health centers & & & 1 & 1 \\
\hline Lighting - primary schools & 4 & 13 & 4 & 21 \\
\hline Lighting - secondary schools & & 3 & 1 & 4 \\
\hline Lighting - teacher dev. center & & 1 & 1 & 2 \\
\hline Solar lanterns & 4 & 1 & 4 & 9 \\
\hline Lighting - teacher households & 7 & 29 & 14 & $50^{\text {a }}$ \\
\hline Solar water pumping & 1 & 1 & & 2 \\
\hline Improved cook stoves & 2 & 2 & & 4 \\
\hline Grand Totals & 18 & 52 & 26 & 96 \\
\hline \multicolumn{2}{|r|}{ Following the program convention, these were considered part of the underlying school } \\
\hline
\end{tabular}

Financially, all projects had a dedicated bank account and were self-generating an income at the six-month mark through their revenue generating activities. This is a significant improvement when compared to country wide community energy projects where only $15 \%$ had both a bank account and income [14]. Three CEDP projects underwent more extensive financial reviews. Unfortunately only 1 of the 3 projects were on track to meet its savings goals, which would ensure sufficient funds for replacement of parts of the long-term.

\section{REFLECTIONS ON THE MODEL}

\section{A. Sustainability Prospects}

Although the CEDP design addressed all the major sustainability issues identified from previous projects, the long-term effectiveness of the model remains to be proven. The balance between technical robustness and the required community contributions of maintenance skills and revenue places a non-trivial expectation on community capacity, i.e. the systems were designed to an acceptable budget with reasonably conservative assumptions and installed using the best locally available equipment, however general maintenance and system faults are still expected over time and responsibility for ongoing operation lies squarely with the community. Two years of community development linked to existing local government structures has left the community with good prospects of revenue generation and the necessary knowledge and network of support for maintenance. However, revenue generation in such remote poor communities is difficult to maintain and grow, local knowledge and personnel also change over time. The actual technical performance of the systems and the continued ability of the community to maintain and operate the systems will be critical to the long term sustainability of the systems and this can only be tested with time. An organization such as CEM which provides ongoing support is therefore critical to sustain the investment made under projects like CEDP.

\section{B. The Role of Communities in Rural Electrification}

A short supply of skills and limited funding for district energy coordination required that the CEDP design a more self-sufficient community model. Malawi has a decentralized governance structure where each district has a significant role in the district level decisions through respective offices (e.g. health and education) under supervision of a district commission. Lack of district level energy offices limit the local support and coordination available for any one project, much less a larger rollout. Community extension workers are insufficiently trained in electrical system management. They serve a vital role of supplying information and training for communities. Finally, lack of pecuniary support requires that all projects self-generate the income needed to cover lifecycle costs for the delivery of the electricity services.

The relatively high performance of the CEDP community energy projects came at the cost of added effort in the development process. The investment required to both establish and then sustain community energy projects requires a systematic review of roles of the stakeholders involved. Limitations of central (and district level) government capabilities to provide basic services oblige communities to lead their own development process; construction of new primary school blocks often require the community to provide the raw materials and organize the labor inputs.

An outstanding result from the CEDP was the communities' high level of engagement in the process and dedication to its success. The projects of CEDP therefore provide a valuable case study for the possibility of a community-based approach to roll-out sustainable energy infrastructure. The wider question the CEDP experience raises is: what is an appropriate and feasible level of responsibility for communities to bear in the supply of off-grid electricity in remote rural locations? Raising this question within the discourse of the Malawian Government is essential for it to be addressed properly. Nonetheless, several suggestions can be cautiously advanced from the evidence presented here. 
Despite the previous national experience with poor performance of off-grid solar PV deployments, a national roll out of solar PV systems for health and education buildings in remote communities across Malawi remains attractive to the Government and international agencies. Prior experience of extensive PV system deployment that is solely a technical process utilizing energy system suppliers and contractors indicates an alternative approach is required to improve sustainability prospects [14]. Large scale-roll out of solar PV installations using the CEDP model would require a significantly larger lead-time and budget to provide the necessary community development inputs. First, the one-time infusions provided through external projects need engagement not only at the community level, but crucially, also at the district and central governance levels. Awareness levels of power system management with renewable generation is extremely low. Coupling this with the business management skills required to run revenue generating activities at the scale needed, the skills requirements are extremely high for a community to manage. Without definitive evidence that the model provides long-term sustainability, a national program for health and education buildings directly replicating this approach should be resisted. The CEDP model was not designed as a roll-out mechanism for energy services to public infrastructure - but instead as a community accessible mechanism to provide electricity access as needed.

However, the desire of communities to develop their own energy services and their potential to contribute to the sustainability of local public infrastructure has been clearly demonstrated. This suggests two choices in the next iteration of community energy projects. With a less ambitious scope, one could scale down projects and training requirements for the community by focusing on relatively more successful activities such as solar lantern distribution and sales, and improved cook-stove production. As the complexity of institutional-based systems is higher, these projects may very well be ruled out. On the other end of the spectrum, capable management of such projects could be developed more systematically through training, education, and financed operation and maintenance. The CEDP model could feasibly provide the basis for a long term, strategic investment in developing community capacity to support national electrification goals. This conclusion is not prescriptive; it is not certain how this gap for training and support should be best filled, for example through public means, private means, or through civil society. Given the fact that many rural institutions providing education and health services are public, it is hard to envision this scenario not requiring a significant expansion of the mandate of district offices; namely by including a dedicated energy office.

\section{CONCLUSIONS}

The results of CEDP have been presented and compared against the known sustainability challenges for off-grid community energy projects in Malawi. The evidence presented suggests the innovations implemented by the model improved the sustainability prospects of the CEDP projects, relative to its peers, and to-date is the most advanced case study of this kind of approach. The CEDP model has demonstrated the ability to foster and support communities in taking forward appropriate technology projects based on their local priorities. It is essential therefore that the evidence on ongoing sustainability for the CEDP systems continues to be assessed and findings made available to influence policy in Malawi and beyond.

The systematic challenges within the energy-sector including the lack of district level energy offices and skill shortages in the community require a high level of selfsufficiency to sustainably manage an energy project. Without addressing these systematic issues, all community energy projects will continue to struggle with sustainability. We have argued that unless an ongoing support mechanism is established, ostensibly through a district energy office, the full potential of community energy projects in Malawi will not be realized.

\section{ACKNOWLEDGMENTS}

MREAP was funded by the Scottish Government from 2012-2015. This work is dedicated to Roy Thompson, a member of the MREAP team who will be missed.

\section{REFERENCES}

[1] Birol, Fatih, "World energy outlook 2012," IEA. Paris. 2012.

[2] C. M. Haanyika, "Rural electrification policy and institutional linkages," Energy Policy, vol. 34, iss. 17, pp. 2977-2993, November, 2006.

[3] M. Kanagawa and T. Nakata, "Assessment of access to electricity and the socio-economic impacts in rural areas of developing countries," Energy Policy, vol 36, no. 6, pp. 2016-2029, 2008.

[4] M. Barron and M. Torero, "Electrification and Time Allocation: Experimental Evidence from Northern El Salvador," no. 63782, University Library of Munich, Germany, 2014.

[5] F. Dincer, "The analysis on photovoltaic electricity generation status, potential and policies of the leading countries in solar energy," Renewable and Sustainable Energy Reviews, vol 15, no. 1, pp.713-720, 2011.

[6] REN21. Renewables 2015 Global Status Report. Paris. 2015.

[7] Birol, Fatih, "World energy outlook 2014," IEA. Paris. 2014.

[8] C. Zalengera, R.E. Blanchard, P.C. Eames, A.M. Juma, M.L. Chitawo, K.T. Gondwe, "Overview of the Malawi energy situation and A PESTLE analysis for sustainable development of renewable energy," Renewable and Sustainable Energy Reviews, vol. 38, pp. 335-347, October, 2014.

[9] J. Kalewekamo, private communication, March 2015.

[10] MCC, "Millennium Challenge Compact between the United States of America Acting Through the Millennium Challenge Corporation and the Republic of Malawi”, 2011.

[11] UIS/ISU. UNESCO Institute for Statistic, n.d. Web. 29 May 2015.

[12] H. Adair-Rohani, et al, "Limited Electricity Access in Health Facilities of Sub-Saharan Africa: A Systematic Review of Data on Electricity Access, Sources, and Reliability," Global Health, Science and Practice vol. 1.2, pp. 249-261, UNESCO. 2013

[13] Strath.ac.uk, "Malawi Renewable Energy Acceleration Programme ", [Online]. Available: http://www.strath.ac.uk/engineering/electronic electricalengineering/ourinternationalprogrammesprojects/malawi renewableenergyaccelerationprogramme/. [Accessed: 12- Feb- 2016].

[14] D. Frame and P. Dauenhauer, "Sustainability of Solar PV Institutions in Malawi," Commissioned Report from the MREAP programme, University of Strathclyde, Glasgow, UK. 2015

[15] C. Currie, G. Davies, and E.W. Young "Process Evaluation of Community Energy Development Programme Projects," Commissioned Report from the MREAP programme, IOD PARC, Edinburgh, UK. 2015. 